\title{
Highly solvent-stable polyimide ultrafine fibrous membranes fabricated by a novel ultraviolet-assisted electrospinning technique via organo-soluble intrinsically negative photosensitive varnishes
}

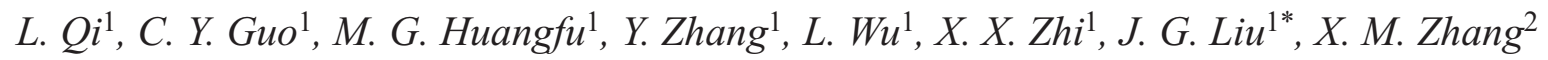 \\ ${ }^{1}$ Beijing Key Laboratory of Materials Utilization of Nonmetallic Minerals and Solid Wastes, National Laboratory of \\ Mineral Materials, School of Materials Science and Technology, China University of Geosciences, 100083 Beijing, China \\ ${ }^{2}$ School of Electrical Engineering, Beijing Jiaotong University, 100044 Beijing, China
}

Received 7 May 2020; accepted in revised form 20 June 2020

\begin{abstract}
A novel fabrication methodology for polyimide (PI) UFMs based on soluble PIs with high solvent durability was developed. As fiber-forming agents, a series of intrinsically negative photosensitive polyimides (PSPIs) with solubility in organic solvents were synthesized by the one-step thermal polymerization of 3,3',4,4'-benzophenonetetracarboxylic dianhydride (BTDA) with three ortho-alkyl-substituted diamine monomers, namely, 3,3',5,5'-tetramethyl-4,4'-diaminodiphenylmethane (TMMDA, for PI-1), 3,3'-dimethyl-5,5'-diethyl-4,4'-diaminodiphenylmethane (DMDEDA, for PI-2), and 3,3',5,5'tetraethyl-4,4'-diaminodiphenylmethane (TEMDA, for PI-3), respectively. Electrospun UFMs were prepared by both traditional electrospinning (PI UFMs) and the novel ultraviolet-assisted electrospinning (UVAES) method (PI-UV UFMs). The effects of the fabrication method on the physical and chemical properties of the electrospun UFMs were investigated systematically. High-efficiency photoinduced crosslinking reactions under ultraviolet (UV) radiation provided the PI-UV UFMs with considerable thermal dimensional stability with the $5 \%$ weight loss temperature over $440{ }^{\circ} \mathrm{C}$. Meanwhile, the derived PI-UV UFMs showed excellent resistance against a polar aprotic solvent, $N, N$-dimethylacetamide (DMAc).
\end{abstract}

Keywords: polymer membranes, photosensitive polyimides, electrospinning, thermal stability, solvent resistance

\section{Introduction}

Electrospinning is one of the most versatile and convenient technologies for preparing polymeric ultrafine fibrous membranes (UFMs) based on fibers with diameters on the scale from sub-nanometres to micrometers [1]. The electrospinning process, which involves the application of an electrostatic force, can produce continuous fibers with both high specific surface areas and ultralow fiber diameters [2]. In recent decades, the electrospinning principle has been fully demonstrated, and new applications have gradually emerged in various areas, including fibrous membranes for filtration, biomedical tissues, nanotube templates, sponges, fiber-reinforced composites, responsive fibers, actuators, and flexible electronics [3-9]. Owing to the physical nature of the main fiber-shaping mechanism, the diameter and surface properties of electrospun ultrafine fibers can be easily adjusted by controlling apparatus parameters such as electric field intensity, spinneret-to-collector distance, and injector flux [10]. In addition, the morphological quality of the electrospun fibers can be further influenced by the properties of the polymer solution, such as viscosity, conductivity, polymer molecular weight and distribution, and surface tension. Moreover, new spinning strategies such as 
coaxial electrospinning, multi-spinneret spinning, and microfluid spinning can be applied to build up fibrous materials with various morphologies, including core-shell structures and vertically or horizontally aligned fibers [11-13]. A variety of raw polymeric materials can be subjected to electrospinning; however, commonly used polymeric spinning sources, such as polystyrene (PS), polyvinyl alcohol (PVA), and polyurethane (PU), have disadvantages such as poor heat tolerance and poor chemical stability, which have limited their applications tremendously [14]. To date, considerable attention has been paid to the fabrication of UFMs using a special series of aromatic heterocyclic polymers, namely, polyimides (PIs) [15]. Nonwoven fibrous PI materials with onedimensional structures have been considered attractive for several decades owing to their favorable advantages of high specific surface areas, ultralow fiber diameters, high environmental stability, and good mechanical properties. Such materials have been used in filtration, oil/water separation, clarification, and other high-tech applications [16-22]. Typically, PI UFMs have been fabricated via electrospinning using either PI precursors or soluble PI resins. In the precursor electrospinning approach, the use of precursors such as poly(amic ester) (PAE) or poly(amic acid) (PAA) requires the heat treatment of the accumulated fibers at temperatures over $300^{\circ} \mathrm{C}$ to achieve conversion to PI by thermal cyclodehydration. The PI UFMs prepared by this process usually exhibit excellent mechanical properties and good chemical stability owing to a high imidization rate and the formation of a thermally crosslinked structure. However, the high-temperature process always causes severe yellowing of the fibers. Moreover, common structural damage, such as microvoid-like defects formed by the evaporation of the generated water by-products, combined with the fusion of fibers can extensively deteriorate the physical and chemical properties of PAA-derived PI UFMs [23-28]. The disadvantages for PAA-derived PI UFMs promote us to develop new approaches for producing PI UFMs. As a more advanced alternative, soluble PI electrospinning allows PI UFMs to be fabricated directly using preimidized PI solutions without subsequent high-temperature imidization treatment. Advantageously, this process has a lower energy cost, and the obtained fibers are paler in color with smooth surfaces. Nevertheless, there are limitations to this process because few soluble PI resins can be directly implemented and the solvent resistance of the spun PI fibers is vastly degraded by the lack of an inter- or intra-molecular crosslinked structure; these disadvantages have impeded the development of UFMs based on soluble PI resins [29-32]. To obtain ultrafine fibers with both of enhanced environment stability and favorable morphologies, the development of new soluble PI resins and electrospinning techniques is imperative.

It has been clearly established that a crosslinked structure plays an important role in enhancing the solvent resistance of polymers [33,34]. Among the variety of methodologies for fabricating polymeric materials with crosslinked structures, photoinduced crosslinking under ultraviolet (UV) irradiation is considered a suitable method for preparing electrospun UFMs with crosslinked topological structures. For instance, Zhu et al. [35] developed bio-based and photo-crosslinked electrospun antibacterial nanofibrous membranes with PVA and chitosan, and evaluated their applicability to air filtration. Meanwhile, Thielke et al. [36] used the thiol-ene reaction to modify electrospun polybutadiene fibers and simultaneous crosslinking under UV irradiation to obtain fibrous mats with superhydrophilic properties. Thus, photo-crosslinking reactions can be considered as a potential approach for improving the performance of materials based on ultrafine PI fibers. The high specific surface area and small diameter of the fibers produced by electrospinning should provide sufficient exposure to the UV irradiation source. Thus, both phase separation and the elongation of polymeric filaments could occur simultaneously with chemical crosslinking reactions to produce a highly crosslinked structure with enhanced environmental stability [37, 38].

Previously, we reported an early attempt to combine in-situ UV-induced crosslinking and electrospinning for fabricating PI UFMs with improved stability against organic solvents using 3,3',4,4'-benzophenonetetracarboxylic dianhydride (BTDA) and diamines with benzene substituents [39]. However, such UFMs suffered from deterioration in solvent resistance because of the increased free molecular volume by lateral bulk benzene side substituents. In the current work, the ultraviolet-assisted electrospinning (UVAES) technique was applied to photocurable PI solutions as the fiber-forming resources. For this purpose, a series of soluble intrinsically negative photosensitive polyimides (PSPIs) consisting of benzophenone (BP) and ortho-alkyl-substituted units were synthesized. These pre-imidized soluble PSPI resins 
were developed in the 1980s and applied for photolithography for semiconductor fabrication [40-44]. The intrinsic PSPIs of this type are auto-photosensitive to UV radiation at the wavelength of $365 \mathrm{~nm}$ (i-line) without extra initiating additions. The obtained photo-patterns can maintain its high resolution even heated into high temperature, expressed benign thermal stability and photosensitivity [4547]. Such PSPIs function via a negative mechanism, where the exposed area undergoes photoinduced crosslinking reactions and maintains the photo-pattern after development in organic solvents [48]. In this study, three different ortho-alkyl-substituted diamine monomers were used to synthesize PSPI resins, whose physicochemical properties were evaluated for subsequent electrospinning. Then, the three PSPI resins were electrospun into UFMs using conventional electrospinning and UVAES procedure. The influences of UV irradiation during electrospinning and such type of PSPI resins on the morphology, thermal properties, optical properties, and solvent resistance were investigated systematically.

\section{Experimental}

\subsection{Materials}

The dianhydride BTDA was purchased from Evonik Industries AG (Frankfurt, Germany) and dried under a vacuum at $180^{\circ} \mathrm{C}$ for 10 hour before use. The diamine 3,3',5,5'-tetramethyl-4,4'-diaminodiphenylmethane (TMMDA) was purchased from POME Sci-tech Co. (Beijing, China), whereas the other two diamines, 3, 3'-dimethyl-5,5'-diethyl-4,4'-diaminodiphenylmethane (DMDEDA) and 3,3',5,5'-tetraethyl4,4'-diaminodiphenylmethane (TEMDA), were obtained from Tokyo Chemical Industry Co. Ltd. (Tokyo, Japan). All the diamines were purified by recrystallization from absolute ethanol before use. The organic solvents $N, N$-dimethylacetamide (DMAc) and $N$-methyl-2-pyrrolidone (NMP) (Sigma-Aldrich China, Shanghai, China) were distillation with calcium hydride $\left(\mathrm{CaH}_{2}\right)$ and phosphorus pentoxide $\left(\mathrm{P}_{2} \mathrm{O}_{5}\right)$ (Sinopharm. Co. Ltd., Shanghai, China), respectively, and stored with $4 \AA$ molecular sieves before use. All other commercially available reagents were used as received without further purification. The UV source (BILON Co. Ltd., Shanghai, China) is consisted of a high-pressure mercury lamp with an emission wavelength of $365 \mathrm{~nm}$ (i-line) and covered with a quartz cooling shell using water as the coolant. The electrospinning device (Yongkang Leye Co.,
Ltd., Beijing, China) had a drum with a fixed size (30 $\mathrm{cm}$ in length and $10 \mathrm{~cm}$ in diameter) and was covered with a layer of aluminum foil as a collector.

\subsection{Synthesis of the intrinsic PSPI resins}

The intrinsically negative PSPI resins with solubility in organic solvents were synthesized via the one-step thermal polycondensation of BTDA with aromatic diamines using isoquinoline, NMP, and toluene as the catalyst, solvent, and dehydrating agent, respectively. A typical procedure for synthesizing the PSPI resins is described here using PI-1 (BTDA-TMMDA) as an example. In a $1000 \mathrm{~mL}$ three-necked flask equipped with a mechanical stirrer and a Dean-Stark apparatus under a nitrogen atmosphere, TMMDA $(25.4370 \mathrm{~g}, 100 \mathrm{mmol})$ was dissolved in NMP $(226.7 \mathrm{~g})$ to give a clear solution. Then, BTDA (32.2240 g, $100 \mathrm{mmol}$ ) was added to the mixture as well as an additional amount of NMP (100.0 g). Isoquinoline $(0.5 \mathrm{~g})$ was then added, and the mixture was stirred for $1 \mathrm{~h}$ under nitrogen. Subsequently, toluene $(250 \mathrm{ml})$ was added and the mixture was heated to $180^{\circ} \mathrm{C}$ for $3 \mathrm{~h}$ to complete the imidization reaction. During the heating process, the water generated by the reaction was continuously removed from the system at the temperature of $130 \sim 140^{\circ} \mathrm{C}$ via its azeotrope with toluene and then collected in the Dean-Stark trap. The dehydration process proceeded for $5 \sim 6 \mathrm{~h}$ until no azeotrope was visually observed in the trap. After the completion of the reaction, the reaction system was cooled to room temperature. The obtained dark yellow viscous solution was slowly poured into a beaker containing an excess amount of ethanol to give a pale brown precipitate. The entire reaction process was conducted in a dark environment under a black cloth to prevent exposure to sunlight. The collected PI-1 resin was dried under vacuum at $80^{\circ} \mathrm{C}$ for $24 \mathrm{~h}$. Yield: $52.4 \mathrm{~g}, 97.0 \%$. ${ }^{1} \mathrm{H}-\mathrm{NMR}$ (DMSO- $d_{6}$, ppm): 8.31-8.18 (m, 6H), 7.16 $(\mathrm{s}, 4 \mathrm{H}), 3.91(\mathrm{~s}, 2 \mathrm{H})$, and $2.07(\mathrm{~s}, 12 \mathrm{H})$.

The other two PSPI resins were synthesized using similar methods with BTDA and the diamine DMDEDA for PI-2 (55.2 g, 97.0\%) and TEMDA for PI-3 (57.9 g, 97.0\%), respectively. In summary, the TMMDA-, DMDEDA-, and TEMDA-based PSPI resins were denoted as PI-1, PI-2, and PI-3, respectively.

PI-2. ${ }^{1} \mathrm{H}-\mathrm{NMR}$ (DMSO- $d_{6}$, ppm): 8.32-8.19 (m, 6H), 7.23-7.18 (m, 4H), $3.99(\mathrm{~s}, 2 \mathrm{H}), 2.40-2.38(\mathrm{~m}, 4 \mathrm{H})$, $2.06(\mathrm{~s}, 6 \mathrm{H})$, and 1.06-1.02 (m, 6H). 
PI-3. ${ }^{1} \mathrm{H}-\mathrm{NMR}$ (DMSO- $\left.d_{6}, \mathrm{ppm}\right): 8.32-8.20$ (m, 6H), $7.24(\mathrm{~s}, 4 \mathrm{H}), 4.04(\mathrm{~s}, 2 \mathrm{H}), 2.38(\mathrm{~s}, 8 \mathrm{H})$, and $1.07-$ $1.02(\mathrm{~m}, 12 \mathrm{H})$.

\subsection{Fabrication of the PSPI ultrafine fibrous membranes}

The UFM fabrication route is shown in Figure 1. Each synthesized PSPI resin was dissolved in DMAc at a solid content of $15 \mathrm{wt} \%$. The PSPI solutions were filtered through a $0.50 \mu \mathrm{m}$ Teflon filter to remove the undissolved contaminations and avoid the formation of obstructions during the spinning procedure. Each prepared PSPI solution was then poured into a $5 \mathrm{ml}$ syringe equipped with a $21 \#$ stainless steel spinneret (0.5 mm inner diameter). The same parameters were used for both of the traditional electrospinning and UVAES procedures (applied voltage between syringe and collector: $15 \mathrm{kV}$, flow rate of pumping system: $0.1 \mathrm{ml} / \mathrm{h}$, the distance between spinneret and rotary drum: $20 \mathrm{~cm}$, collection speed: $5 \mathrm{rpm}$, clockwise rotation, and relative humidity: $30 \pm 2 \%$ ). The primary difference between these two methods was that the high-pressure mercury lamp (maximum wavelength: $365 \mathrm{~nm}$ ) at a fixed temperature of $3-4^{\circ} \mathrm{C}$ by the ice-water cooling was located $5 \mathrm{~cm}$ above the collector drum during the UVAES procedure. Continuous UV exposure was applied during the entire spinning process.

\subsection{Characterization methods}

The absolute viscosity of the synthesized PSPI resins was measured using a Brookfield DV-II+ Pro viscometer (Middleboro, USA). An Ubbelohde viscometer with $0.5 \mathrm{~g} / \mathrm{d} 1 \mathrm{NMP}$ solutions was used for determining the inherent viscosities of the resins at $25^{\circ} \mathrm{C}$. A Shimadzu gel permeation chromatography (GPC) system (Kyoto, Japan) with NMP as the mobile phase (flow rate: $1.0 \mathrm{ml} / \mathrm{min}$ ) was utilized for determining the weight-average molecular weight $\left(M_{\mathrm{w}}\right)$ and the number-weight molecular weight $\left(M_{\mathrm{n}}\right)$ of the PIs. The solubility of the synthesized resins

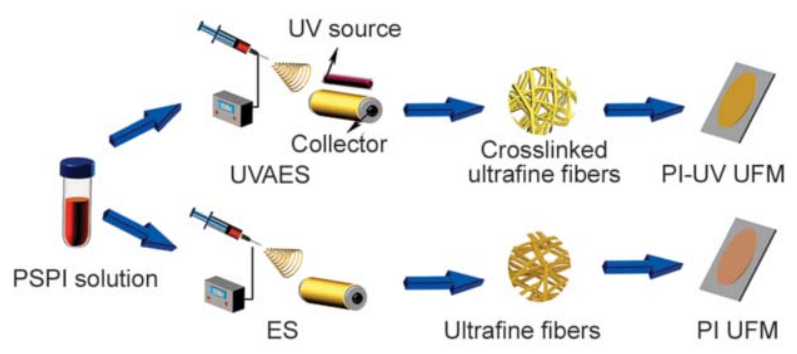

Figure 1. The fabrication route for the PI and PI-UV UFMs. was determined as follows: $1.5 \mathrm{~g}$ of each PSPI resin was dissolved in $8.5 \mathrm{~g}$ of different test solvents (solid content: $15 \mathrm{wt} \%$ ) and then allowed to stand for $24 \mathrm{~h}$ in black at room temperature. The solubility was divided into three levels: completely soluble $(++)$, partly soluble $(+)$, and insoluble $(-)$. Complete solubility was defined as a homogeneous and clear solution in which no precipitation, gel formation, or phase separation was observed.

The chemical structures of the PSPI resins were confirmed by hydrogen nuclear magnetic resonance ( $\left.{ }^{1} \mathrm{H}-\mathrm{NMR}\right)$ spectroscopy using a Bruker Avance II 400 spectrometer (Karlsruhe, Germany) with deuterated dimethyl sulfoxide (DMSO- $d_{6}$ ) as the solvent at $400 \mathrm{MHz}$. Attenuated total reflectance Fourier transform infrared (ATR-FTIR) spectroscopy using a Thermo Fisher Scientific Nicolet 6700 spectrometer (Waltham, USA) was used to evaluate the photochemical reaction mechanism and the functional group composition of the PI UFMs. The crosslinking degree was calculated using the internal standard method according to Equation (1):

Crosslinking degree $=\frac{\left(\frac{A_{1680}}{A_{1485}}\right)_{\mathrm{PI}}}{\left(\frac{A_{1680}}{A_{1485}}\right)_{\mathrm{PI}-\mathrm{UV}}} \cdot 100$

where $A_{1680}$ is the strength of the carbonyl group absorption in BTDA, whereas the $A_{1485}$ is the absorption strength of $\mathrm{C}=\mathrm{C}$ in the benzene unit, which was used as the internal standard. The subscripts 'PI' and 'PI-UV' refer to the UFMs prepared by traditional electrospinning and UVAES, respectively.

The photosensitivity of the derived PSPI was evaluated by an i-line $(365 \mathrm{~nm})$ photolithography procedure using a photolithographic machine (MA-6, SUSS MicroTec, Garching, Germany). The PI-1 solution (solid content: $10 \mathrm{wt} \%$, viscosity: $3200 \mathrm{mPa} \cdot \mathrm{s}$ ) was spin-coated onto a 3 inch silicon wafer at the speed of $2000 \mathrm{rpm}$ for $20 \mathrm{~s}$ and then dried on a hot plate at $70^{\circ} \mathrm{C}$ for $90 \mathrm{~s}$. Then, the wafer was exposed to ultraviolet light with a wavelength of $365 \mathrm{~nm}$ (i-line) for $70 \mathrm{~s}$ using the photolithography machine. After exposure, the wafer was developed in pure $\mathrm{N}, \mathrm{N}$-dimethylformamide (DMF) for $3 \mathrm{~min}$ at room temperature. Then, the wafer was sprayed with butyl acetate for $30 \mathrm{~s}$ at room temperature. At last, the wafer was post-baked at $300^{\circ} \mathrm{C}$ for $30 \mathrm{~min}$ in nitrogen. The photolithography patterns of PI- 1 were observed with the field emission scanning electron microscopy (FE-SEM; JEOL JSM-6700F, Tokyo, Japan). 
The micro-morphologies of the obtained microfibers were observed by field emission scanning electron microscopy (FE-SEM; JEOL JSM-6700F, Tokyo, Japan) with an acceleration voltage of $10 \mathrm{kV}$. A thin layer of $\mathrm{Pt} / \mathrm{Pd}$ was sputtered on the surface of the membranes. The Image-J software was used for the statistical analysis of the fiber diameters, and the average values were calculated from 100 single fibers. To determine the heat resistance characteristics of the UFMs, Thermal gravimetric analysis (TGA) was conducted using a TA Instruments TGA Q50 analyzer (New Castle, USA) at the heating rate of $20^{\circ} \mathrm{C} / \mathrm{min}$ from 50 to $750^{\circ} \mathrm{C}$ under nitrogen. The glass transition behavior of the UFMs was evaluated using a Netzsch DSC 204 HP (Selb, Germany) differential scanning calorimetry (DSC) system at a heating rate of $10^{\circ} \mathrm{C} / \mathrm{min}$ up to $400^{\circ} \mathrm{C}$ under nitrogen. The water contact angles (WCAs) of the PI fibers were measured using a Dataphysics OCA40 Micro automatic video microcontact angle measuring instrument (Stuttgart, Germany). For the WCA measurements, $5 \mu$ of deionized water was dropped onto the flat surface of the fibrous membrane, and the static value was determined from the average of five measurements. The reflectance of each PI UFM was measured by ultraviolet-visible (UV-Vis) spectroscopy using a Hitachi U-3210 spectrophotometer (Tokyo, Japan) at room temperature. An X-rite Ci 7860 spectrophotometer (Grand Rapids, Michigan, USA) was used to determine the whiteness index (WI) of the PI UFMs. The WI values were calculated using Equation (2):

$$
\mathrm{WI}=100-\sqrt{\left(100-L^{*}\right)^{2}+a^{* 2}+b^{* 2}}
$$

where $L^{*}$ is the lightness of the UFMs, and $a^{*}$ and $b^{*}$ are the color parameters of the samples, respectively. The solvent resistance of the fabricated PI UFMs was evaluated via immersion tests, as follows. Each UFM was cut to a size of $35 \mathrm{~mm}$ (length) by $25 \mathrm{~mm}$ (width) by $0.2 \mathrm{~mm}$ (thickness) and then gradually immersed in a glass vessel containing $50 \mathrm{ml}$ of the aprotic polar organic solvent DMAc. Once completely submerged, the UFM was allowed to soak for $30 \mathrm{~s}$. Subsequently, the solvent resistance of the UFM was evaluated based on both SEM images and visual observations.

\section{Results and discussion}

\subsection{Polymer synthesis}

Three organic-soluble PSPI resins were synthesized by a one-step direct polycondensation reaction between BTDA and various ortho-alkyl-substituted diamine monomers, as shown in Figure 2. The designed PI structures are expected to possess good solubility, high thermal stability, and auto-photosensitivity owing to the combination of an aromatic heterocyclic ring structure and active carbonyl groups.

The molecular weights and inherent viscosities of the PI resins are summarized in Table 1 . The prepared PSPI resins all had high $M_{\mathrm{n}}$ values of 50639 $106604 \mathrm{~g} / \mathrm{mol}$ with polydispersity indices (PDI; $\left.M_{\mathrm{w}} / M_{\mathrm{n}}\right)$ of $1.77-1.98$, indicating that the resins possessed both a relatively high polymerization degree and a narrow distribution. The inherent viscosities of the PI resins were in the range of 1.00-1.29 $\mathrm{dl} / \mathrm{g}$ at room temperature $\left(25^{\circ} \mathrm{C}\right)$ in NMP (Table 1), which suggested moderate to high molecular weights of the PI resins.
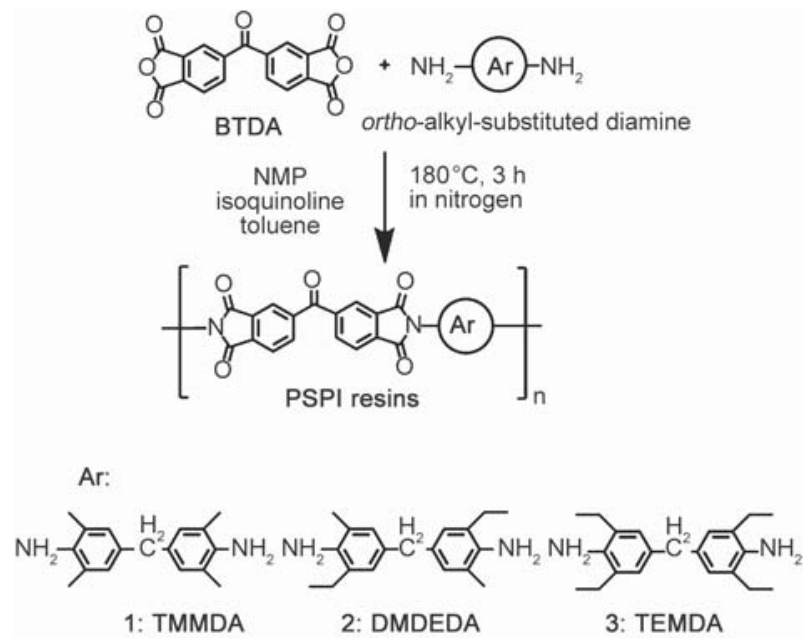

Figure 2. Synthesis of the PI resins.

Table 1. Absolute molecular weight and solubility of the PSPIs.

\begin{tabular}{|c|c|c|c|c|c|c|}
\hline \multirow[t]{2}{*}{ PI } & \multirow[t]{2}{*}{ Dianhydride } & \multirow[t]{2}{*}{ Diamine } & \multirow{2}{*}{$\begin{array}{l}{[\eta]_{\text {inh }}{ }^{2}} \\
{[\mathbf{d l} / \mathrm{g}]}\end{array}$} & \multicolumn{3}{|c|}{$\begin{array}{c}\text { Molecular weight } \\
{[\mathrm{g} / \mathrm{mol}]}\end{array}$} \\
\hline & & & & $M_{\mathrm{n}}$ & $M_{\mathrm{w}}$ & PDI \\
\hline PI-1 & BTDA & TMMDA & 1.00 & 50639 & 89827 & 1.77 \\
\hline PI-2 & BTDA & DMDEDA & 1.29 & 106604 & 203937 & 1.91 \\
\hline PI-3 & BTDA & TEMDA & 1.18 & 86247 & 170910 & 1.98 \\
\hline
\end{tabular}

anherent viscosities measured with a PI resin at a concentration of $0.5 \mathrm{~g} / \mathrm{dl}$ in NMP at $25^{\circ} \mathrm{C}$. 
Solution electrospinning is an important method for the fabrication of PI UFMs, in which the solubility of PI resins is a crucial factor. High solubility is usually ascribed to the strong interactions between the polymer and solvent, which allowing benign swelling and disentanglement of the polymer chains. Sufficiently high solubility in organic solvents is a necessary requirement for PIs to achieve ultrafine fibers with suitable morphologies and adequate optical properties. The solubility was largely controlled by the molecular weight and the molecular structure of the PI resins. Herein, the solubility of the negative PSPI resins was evaluated using seven typical solvents, including the polar solvents DMAc, DMF, and NMP as well as the less polar solvents, cyclopentanone (CPA), tetrahydrofuran (THF), $\mathrm{CHCl}_{3}$, and $\gamma$-butyrolactone (GBL), as shown in Table 2. All the PSPI resins exhibited good solubility in the polar aprotic solvents (NMP, DMF, and DMAc), with clear and homogeneous solutions obtained at a solid content of $15 \%$ at room temperature for $24 \mathrm{~h}$. The resins were also completely or mostly soluble in CPA and THF. The PI resins only showed inferior solubility in $\mathrm{CHCl}_{3}$ and GBL.

The production of UFMs with good morphologies and reasonable fiber diameter distributions was highly dependent on the balance between Coulombic forces, surface tension, and the viscoelasticity of the polymers. To obtain relatively thin and uniformly distributed fibers required the determination of appropriate spinning parameters for the PI fiber-forming agents, such as solvent solubility, viscosity, concentration, spinneret-collector distance, and spinning voltage. Suitable solvents and solid contents for the PIs should be determined for the fabrication of the UFMs. When considering the solution properties of the fiber-forming agents, the solid content and viscosity of the polymer solution should be investigated comprehensively. Suitable solution properties favor the fabrication of ultrafine fibers with good surface morphologies and appropriate diameters. The high

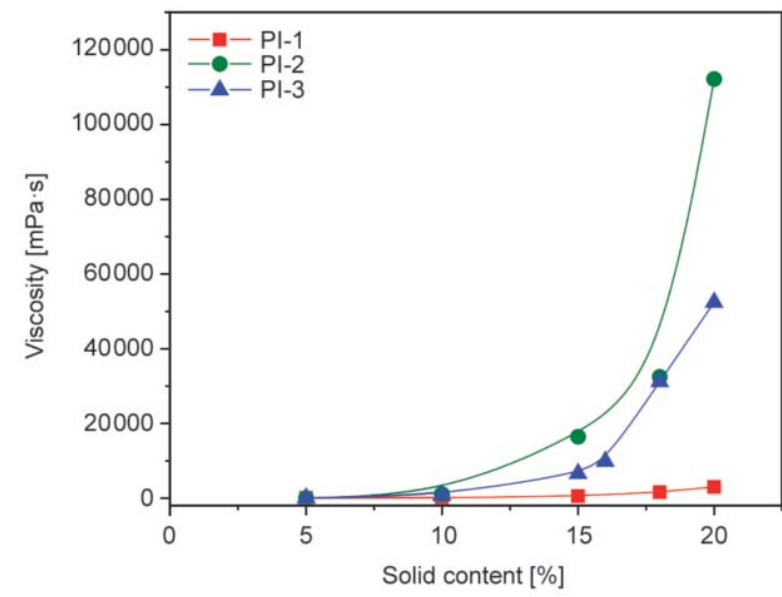

Figure 3. Relationship between absolute viscosities and solid contents of PI resins.

viscosity of the polymer solution can result in the formation of excessively thick fibers. On the contrary, if the concentration is too low, the rapid evaporation of the solution and weak entanglement between the molecular chains make it difficult for the PI resins to overcome the Rayleigh instability from the electric field, which can lead to fibers with bead defects. As shown in Figure 3, an apparent increase in the viscosity occurred as the solid content of the PI solution increased. This is because the mobility of the polymer chains was reduced by chain entanglement at higher solution concentration, which impeded the re-ordering of the molecular chains and thus increased the solution viscosity. Furthermore, an obvious change in the slope of the plots was observed when the solid content increased from 15 to $20 \mathrm{wt} \%$, which corresponds to the beginning of cohesion between the PI molecular chains. Owing to the preliminary entanglement and the interactions between molecular chains, the jetted polymer could maintain a sufficient tension to protect its structure from damage when passing through the high-voltage electric field. It has been demonstrated that a solid content near where the change in slope was observed will provide polymer jets with a suitable viscosity for electrospinning thin and bead-free ultrafine

Table 2. Solubility in organic solvents of the PSPIs.

\begin{tabular}{|c|c|l|c|c|c|c|c|c|c|}
\hline \multirow{2}{*}{ PI } & \multirow{2}{*}{ Dianhydride } & \multirow{2}{*}{ Diamine } & \multicolumn{9}{|c|}{ Solvent $^{\text {a }}$} \\
\cline { 5 - 10 } & & & NMP & DMAc & DMF & GBL & CPA & THF $_{|c|}$ CHCl $_{\mathbf{3}}$ \\
\hline PI-1 & BTDA & TMMDA & $++^{\mathrm{b}}$ & ++ & ++ & - & ++ & ++ & - \\
\hline PI-2 & BTDA & DMDEDA & ++ & ++ & ++ & - & ++ & ++ & + \\
\hline PI-3 & BTDA & TEMDA & ++ & ++ & ++ & - & + & ++ & - \\
\hline
\end{tabular}

aGBL: $\gamma$-butyrolactone; CPA: cyclopentanone; THF: tetrahydrofuran;

${ }^{b}:++$ : Wholly soluble at room temperature, +: Partially soluble, -: Insoluble. 
fibers. Hence, for UFM fabrication, a solid content of $15 \mathrm{wt} \%$ was used for all three PI solutions as fiber-forming agents.

\subsection{Structure and photochemical mechanism of the UFMs}

The soluble intrinsically negative PSPI resins (PI-1PI-3) were fabricated into UFMs by traditional electrospinning and UVAES procedure. The chemical structures of the PI UFMs were confirmed using ATR-FTIR and ${ }^{1} \mathrm{H}-\mathrm{NMR}$ spectroscopy, respectively. In the ATR-FTIR spectra shown in Figure 4, the absorption peaks at 2980 and $2920 \mathrm{~cm}^{-1}$ correspond to the asymmetric and symmetric vibrations of the methyl $\left(-\mathrm{CH}_{3}\right)$ groups in the polymers. Furthermore,

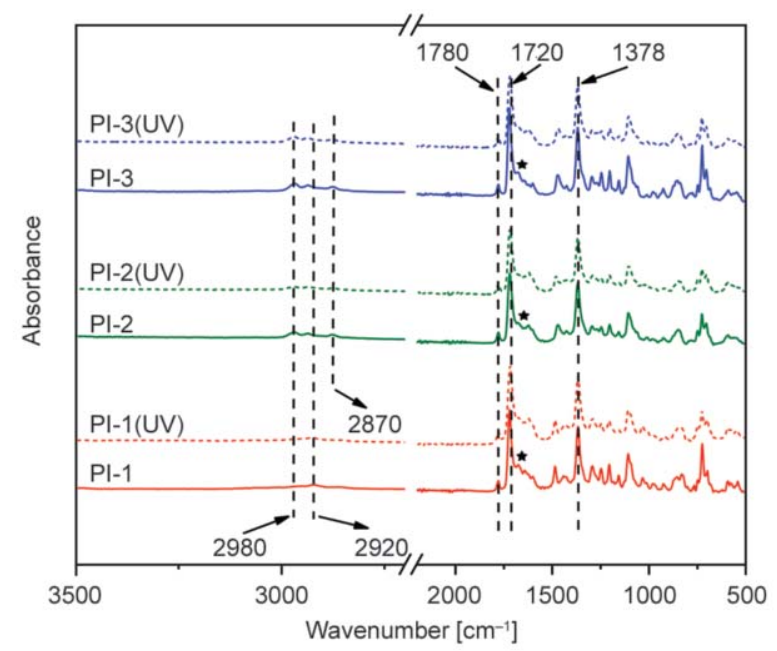

Figure 4. ATR-FTIR spectra of PI and PI-UV UFMs. the absorption peak at $2870 \mathrm{~cm}^{-1}$, which corresponds to the symmetric vibration of $-\mathrm{CH}_{2}-$ structures, confirmed the existence of ethyl $\left(-\mathrm{CH}_{2} \mathrm{CH}_{3}\right)$ groups in PI-2 and PI-3. The characteristic absorption peaks at 1780 and $1720 \mathrm{~cm}^{-1}$ are attributed to the asymmetric and symmetric stretching vibration of carbonyl moieties, respectively. In addition, the absorption peak at $1378 \mathrm{~cm}^{-1}$, which corresponds to $\mathrm{C}-\mathrm{N}-\mathrm{C}$ stretching vibrations, provides evidence for successful imide formation.

More importantly, the intensity of the absorption peak at $1680 \mathrm{~cm}^{-1}$, which represents the ketone carbonyl group of BTDA units in PI UFMs (labelled as pentagram in Figure 4), showed an apparent decrease in all of the PI-UV UFMs, as can be illustrated in Figure 5. This phenomenon provides sufficient evidence for the occurrence of photoinduced crosslinking. As shown in Figure 5b, this mechanism of the photochemical crosslinking reaction for autosensitive PSPI has been well established [40-44]. Following UV irradiation, the activated triplet ketone carbonyl can abstract a hydrogen from an adjacent ortho-substituted alkyl group in the diamine moiety, leading to the formation of free radicals that subsequently generate a crosslinked structure by inter/intramolecular reactions of the polymer chains. This mechanism was confirmed by monitoring the absorption intensity of the carbonyl group from the benzophenone moiety (Figure 5b). According to Equation (1), the calculated crosslinking degree is $99.1 \%$ for
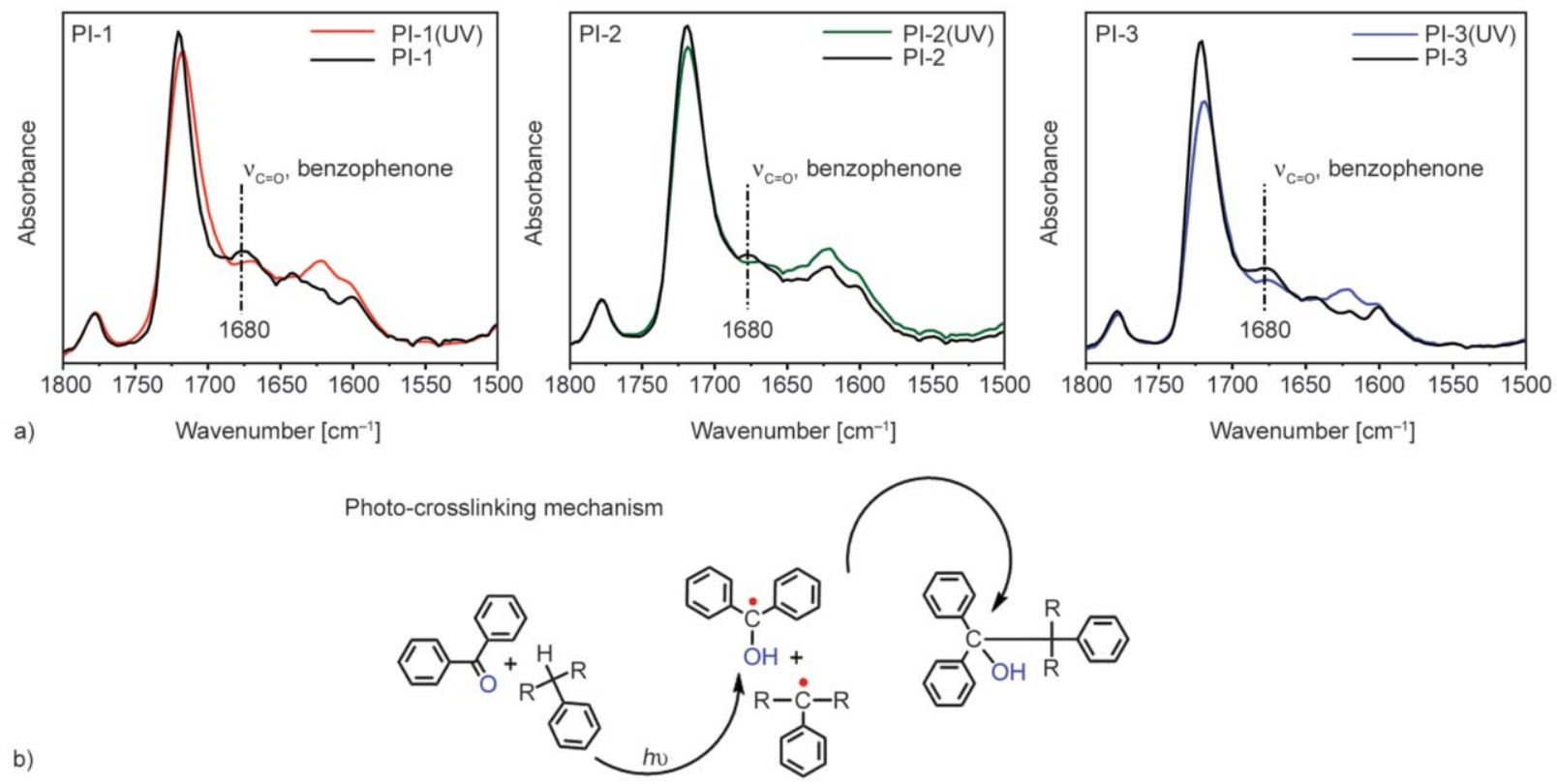

b)

Figure 5. (a) ATR-FTIR spectra of PI and PI-UV UFMs in the range of 1500 to $1800 \mathrm{~cm}^{-1}$ and (b) photo-crosslinking mechanism of the intrinsic negative PSPIs. 
PI-1(UV), $68.6 \%$ for PI-2(UV), and $75.7 \%$ for PI-3(UV), respectively. Thus, the UV exposure in electrospinning process indeed induced the occurrence of the photo-crosslinking reaction of the PSPIs although the exposure time was quite short, which is on one hand due to high sensitivity of the PSPI to i-line exposure, and on the other hand due to the high specific surface area and ultrathin fiber diameters of the thin PSPI fibers. This offered sufficient contact between the electrospun microfibers under UV irradiation during the transitory time from the spinneret to the collector. In practical UVAES fabrication, the PI molecular chains in the charged micro-jet are expected to be in a partially extended state because of the induced plastic stretching; therefore, the majority of photochemical reactions are likely to result in intermolecularly crosslinked structures, although the occurrence of intra-molecular crosslinking cannot be neglected. The realization of effective photopolymerization during the electrospinning process confirms the UVAES procedure as a practical method for fabricating PI UFMs with in-situ crosslinked structures.

To further understand the photosensitivity of the PI resin solution, the photolithography behaviors of the typical PI-1 resin solution were evaluated and the patterns were shown in Figure 6. It can be clearly observed that the PI-1 solution exhibited good photosensitivity to i-line (365 nm) UV light. The photolithography patterns with the resolution around $20 \mu \mathrm{m}$ were achieved. The good photosensitivity of the current PI solution made it possible to fabricate high quality PI UFMs vis UVAES procedure.

The good solubility of the PI UFMs in polar solvents DMSO made it possible to confirm the chemical

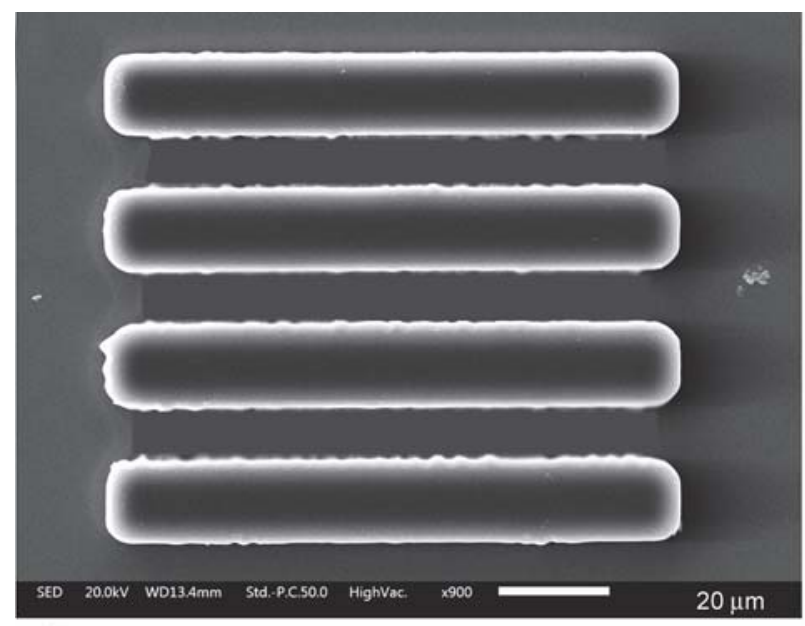

a) structures of the PI UFMs with NMR measurements. In the ${ }^{1} \mathrm{H}-\mathrm{NMR}$ spectra of the polymers, all of the hydrogen proton signals were in good accordance with the designed molecular structures. The absorptions of the aromatic protons in the PIs all appeared at the farthest downfield (chemical shift: $7.0 \sim 8.5 \mathrm{ppm}$ ) in the spectra, owing to the strong electron-withdrawing carbonyl groups in the dianhydride moiety. On the contrary, the aliphatic protons, such as the ones in $-\mathrm{CH}_{2}-,-\mathrm{CH}_{2} \mathrm{CH}_{3}$, or $-\mathrm{CH}_{3}$ showed absorptions at the farthest upfield (chemical shift: $1.0 \sim 4.2 \mathrm{ppm}$ ) in the spectra. These results demonstrate that the target PSPI resins were successfully synthesized and fabricated into PI UFMs.

\subsection{Morphology of the ultrafine fibers}

Representative morphologies of the fabricated PI UFMs are shown in Figure 7. Highly random aligned microfibers with smooth surfaces were obtained by both of normal electrospinning and UVAES procedures. The fiber diameters could be further controlled by adjusting parameters such as the injection speed, electric field intensity, and ejection distance. No pinhole-like defects or bead structures were observed in the SEM images of the fibers, which can be explained by the balance achieved between the surface tension, viscoelastic force, and electrostatic repulsion in the spinning system. When a suitable solid content of a PI resin is used, the viscoelastic force, as the prominent force of the jet, aids in the formation of beadfree fibers with good surface appearance. The UFMs consist of loose porous multilayers with net-shaped structures formed from fibers with a uniform diameter distribution. The fiber diameters increased from 249 to $426 \mathrm{~nm}$ as the content of alkyl side chains

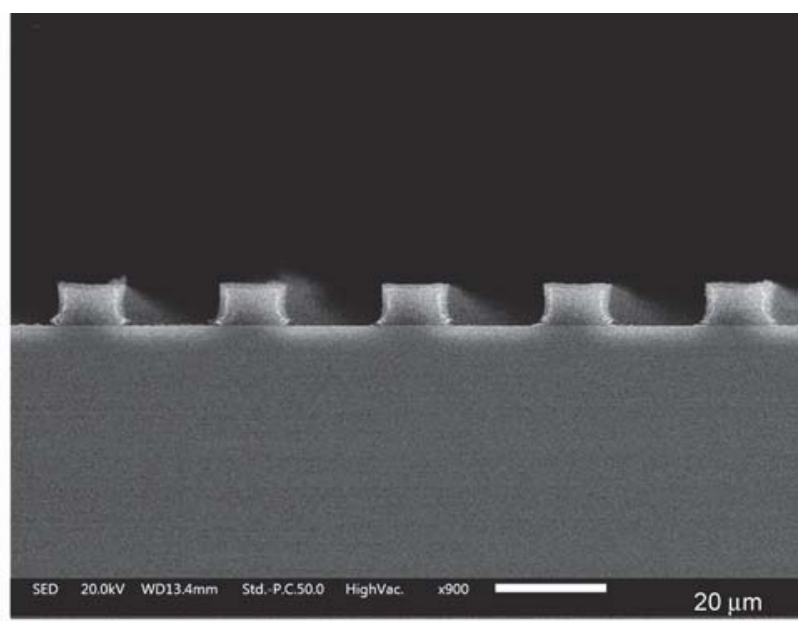

b)

Figure 6. Patterns of the PI-1 by i-line photolithography procedure. (a) Top-sectional view, (b) cross-sectional view. 

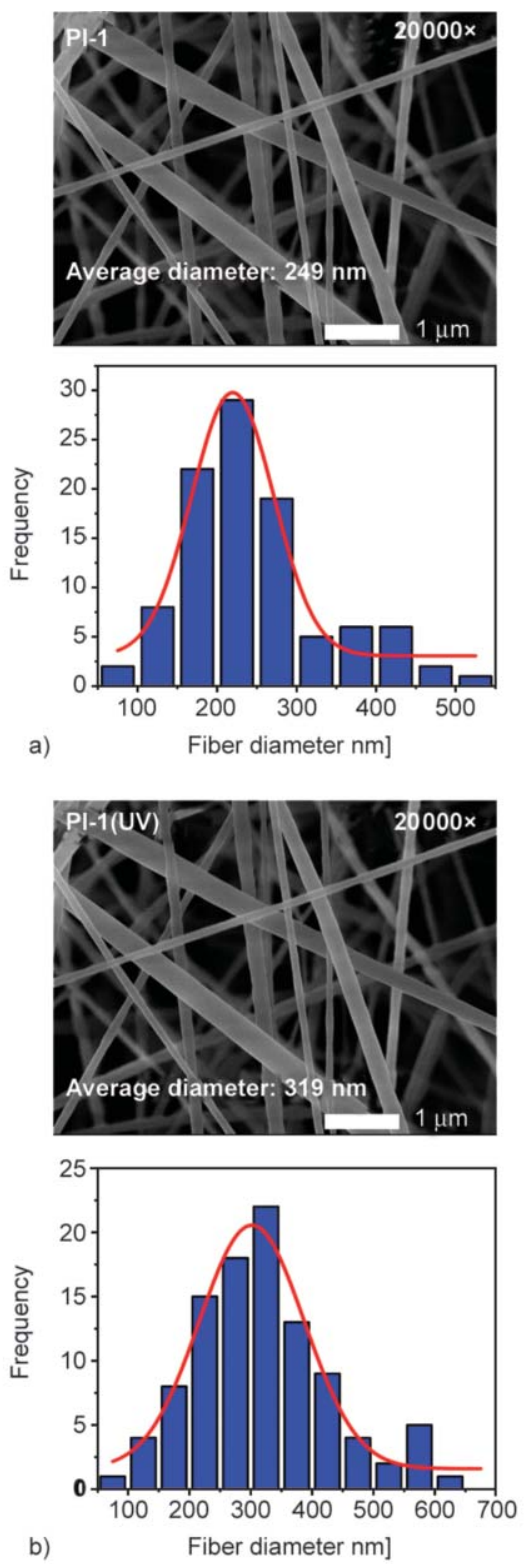
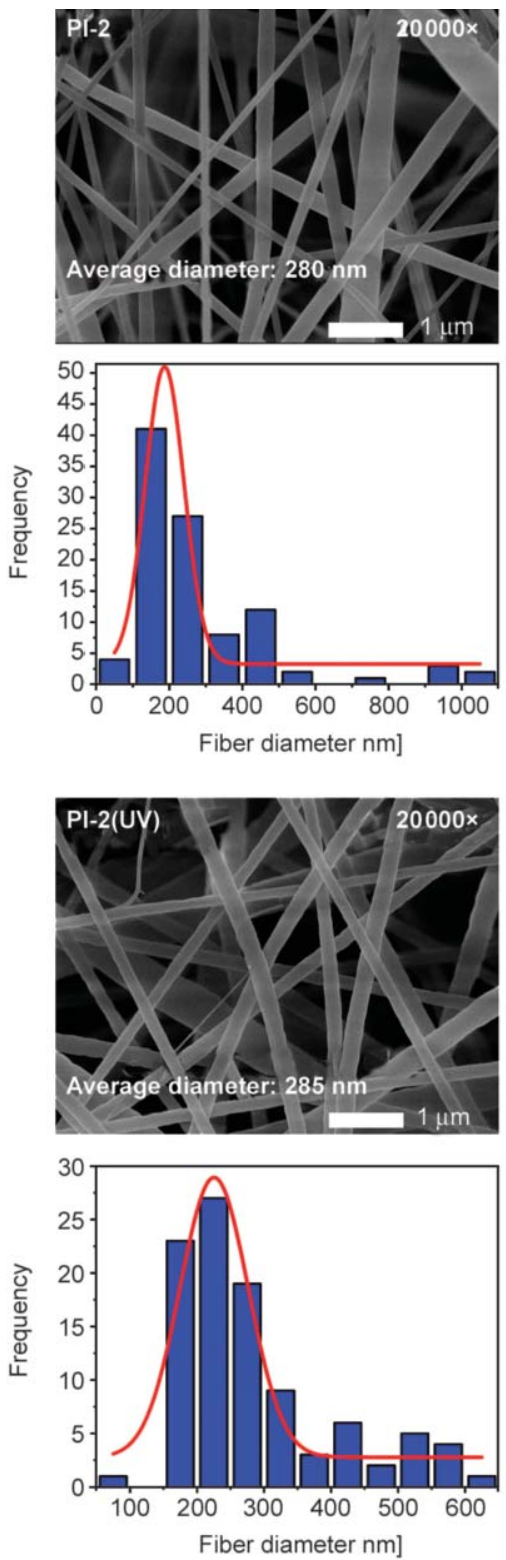
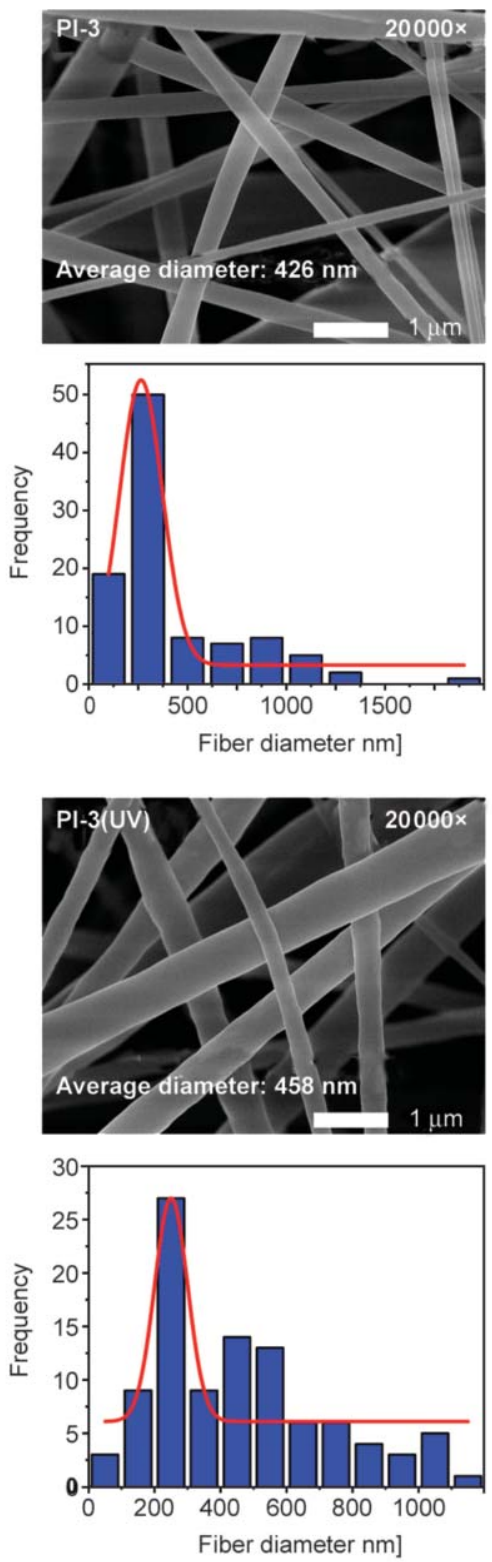

Figure 7. FE-SEM images of PI and PI-UV UFMs. (a) PI UFMs; (b) PI-UV UFMs.

increased from PI-1 to PI-3 (Figure 7a). Although the PI-2 resin had the highest viscosity, the diameter of the PI-2 fibers was lower than that of the PI-3 fibers. Furthermore, the fibers of PI-2 and PI-3 showed uniform diameter distributions, whereas the diameter distribution of PI-1 was broader. These phenomena showed that unlike ordinarily spun PI polymers, for this type of soluble intrinsically PSPI, the diameters of the spun fibers were not only affected by the viscosity of the polymers but also by the chemical structure of the PI resin. Moreover, the uniformity coefficient of the diameter of the spun fibers was mainly controlled by the viscosity of the PI resins. UV irradiation had no obvious influence on the surface morphology of the PI fibers, with the exception of a slight increase in the average diameter (Figure 7b).
This increase can be attributed to the enhancement in molecular chain entanglement among the PI-UV UFMs caused by photocrosslinking, which increased the surface tension of the spray jet and led to a larger diameter.

\subsection{Thermal properties of the PI UFMs}

The thermal properties of the PI and PI-UV UFMs were investigated by TGA and DSC, respectively and the data are summarized in Table 3. According to the TGA plots shown in Figure 8a, the UFMs prepared by both of traditional electrospinning and UVAES procedures all exhibited good heat resistance with thermal decomposition temperatures $\left(T_{5 \%}\right.$, corresponding to the temperature at which $5 \%$ weight loss occurs) in the range of $443.8 \sim 481.3^{\circ} \mathrm{C}$ and residual 
Table 3. Thermal properties of PI UFMs.

\begin{tabular}{|l|c|c|c|c|}
\hline & $\begin{array}{c}\boldsymbol{T}_{\mathbf{g}} \mathbf{a} \\
{\left[{ }^{\circ} \mathbf{C}\right]}\end{array}$ & $\begin{array}{c}\boldsymbol{T}_{\mathbf{5 \%}}{ }^{\mathbf{b}} \\
{\left[{ }^{\circ} \mathbf{C}\right]}\end{array}$ & $\begin{array}{c}\boldsymbol{T}_{\mathbf{1 0 \%}}{ }^{\mathbf{b}} \\
{\left[{ }^{\circ} \mathbf{C}\right]}\end{array}$ & $\begin{array}{c}\boldsymbol{R}_{\mathbf{w 7 4 0}}{ }^{\mathbf{c}} \\
{[\mathbf{\%}]}\end{array}$ \\
\hline PI-1 & 320.5 & 481.3 & 506.4 & 57.6 \\
\hline PI-1(UV) & null & 448.9 & 499.1 & 56.7 \\
\hline PI-2 & 304.8 & 453.9 & 489.1 & 60.2 \\
\hline PI-2(UV) & null & 443.8 & 486.6 & 59.9 \\
\hline PI-3 & 285.4 & 471.5 & 494.1 & 59.4 \\
\hline PI-3(UV) & null & 463.7 & 498.9 & 57.4 \\
\hline
\end{tabular}

${ }^{\mathrm{a}} T_{\mathrm{g}}$ : Glass transition temperature measured by DSC;

${ }^{\mathrm{b}} T_{5 \%}, T_{10 \%}$ : Temperatures at 5 and $10 \%$ weight loss, respectively;

${ }^{\mathrm{c}} R_{\mathrm{w} 740}$ : Residual weight ratio at $740^{\circ} \mathrm{C}$ in nitrogen.

weight ratios of $56.7 \sim 60.2 \mathrm{wt} \%$ at $740{ }^{\circ} \mathrm{C}$. In addition, the TGA results revealed a slight decrease in the thermal stability of the UV-irradiated UFMs, as the $T_{5 \%}$ values decreased slightly for the PI-UV UFMs, mainly because of a change in the molecular structure of the fibers caused by the transformation of benzophenone into benzhydrol, which is less thermally stable. Despite this slight deterioration, the thermal stability of the PI-UV UFMs remains sufficiently high for high-temperature applications because of the successful photoinduced crosslinking reaction.

The glass transition temperature $\left(T_{\mathrm{g}}\right)$ values of one polymer indicate its heat durability and reliability, which is also a critical indicator for the temperature range in which the current PI UFMs can be applied. Below $T_{\mathrm{g}}$, PI UFMs are in a glassy state without obvious chain motions. Above $T_{\mathrm{g}}$, the provided energy is sufficient to overcome intermolecular attraction, and the resulting chain motion breaks the fibrous structure and causes the deterioration of the mechanical properties of the UFMs. The $T_{\mathrm{g}}$ values of the PI UFMs, as determined by DSC curves shown in Figure $8 \mathrm{~b}$, were between $285.4 \sim 320.5^{\circ} \mathrm{C}$ and showed

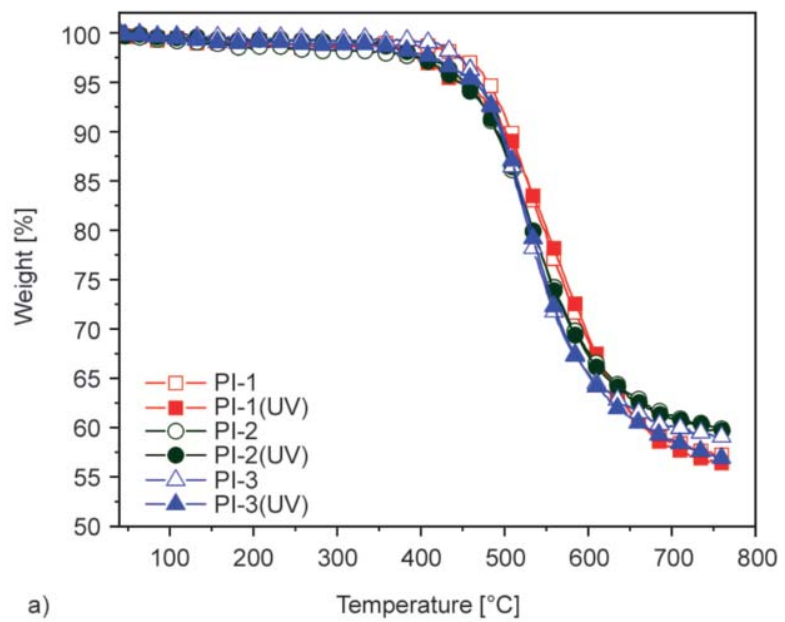

an obvious decrease as the amount of alkyl side chains in the diamine increased. This tendency can be ascribed to the increased number of alkyl branches occupying a larger molecular free volume and weakening the interactions between PI molecular chains. However, the $T_{\mathrm{g}}$ values of the PI-UV UFMs were not clearly observed in the investigated temperature range. This result indicates that the thermal movement of the molecular chains was effectively hindered by the photo-crosslinking reaction, thus providing the UV-exposed fibers with improved thermal dimensional stability.

\subsection{Optical properties of the PI UFMs}

The optical properties of the UFMs were investigated using UV-Vis spectroscopy, and WI measurements and the data are tabulated in Table 4. As shown in the UV-Vis spectra of the PI UFMs (Figure 9a), for both of conventionally spun and UVAES spun UFMs, the reflectance values increased rapidly from 300 to $400 \mathrm{~nm}$ and then increased more slowly, reaching a stable value above $550 \mathrm{~nm}$. The reflectance at $457 \mathrm{~nm}\left(R_{457}\right)$, known as the blue-ray whiteness, is typically used to evaluate the color properties of fibrous membranes. The $R_{457}$ values of the PI UFMs were all higher than $75 \%$ but decreased as the fiber diameter increased, which was attributed to thinner fibers providing more cavities for light to reflect from the membrane surface. The PI-UV UFMs also exhibited decreased $R_{457}$ values compared with the corresponding PI UFMs, which might be attributed to a color transformation derived from the photo irradiation process [49].

To further understand the optical properties of the membranes, the WI values were determined, as shown

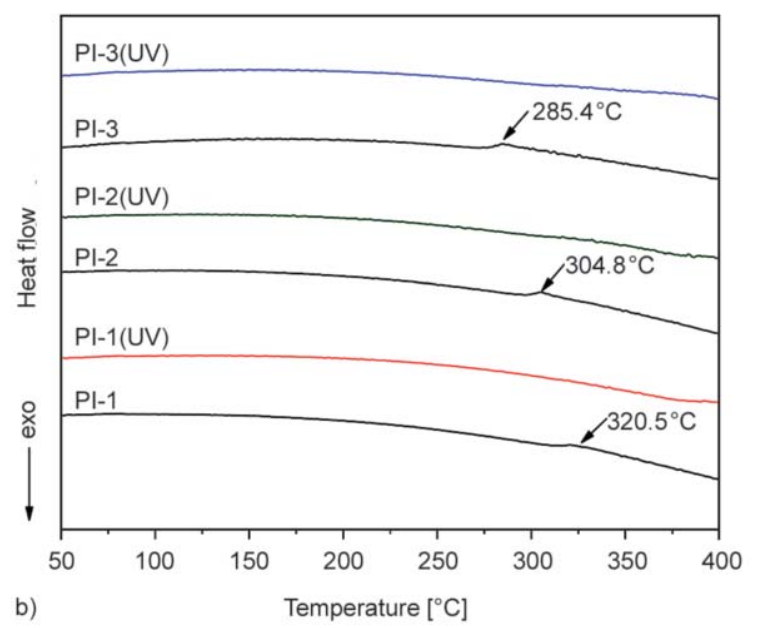

Figure 8. Thermal properties of PI ultrafine fibrous membranes. (a) TGA; (b) DSC. 
in Figure 9b. The WI values of the PI-UV UFMs fabricated using PI-1, PI-2, and PI-3 were 81.75 ,

Table 4. Optical properties of PI and PI-UV UFMs.

\begin{tabular}{|l|c|c|r|r|c|}
\hline \multicolumn{1}{|c|}{ PI } & $\boldsymbol{R}_{\mathbf{4 5 7}^{\mathbf{a}}}$ & $\boldsymbol{L}^{\boldsymbol{*}}$ & \multicolumn{1}{c|}{$\boldsymbol{a}^{\text {* }}$} & \multicolumn{1}{c|}{$\boldsymbol{b}^{\text {* }}$} & $\mathbf{W I}^{\mathbf{b}}$ \\
\hline PI-1 & 87.0 & 91.98 & -1.31 & 6.34 & 89.69 \\
\hline PI-1(UV) & 75.4 & 92.46 & 0.31 & 16.61 & 81.75 \\
\hline PI-2 & 76.7 & 89.44 & -0.81 & 9.26 & 79.15 \\
\hline PI-2(UV) & 69.1 & 90.56 & -1.35 & 19.61 & 78.19 \\
\hline PI-3 & 75.8 & 88.73 & -0.46 & 9.34 & 85.36 \\
\hline PI-3(UV) & 67.3 & 89.59 & -0.91 & 17.03 & 80.02 \\
\hline
\end{tabular}

${ }^{\mathrm{a}} R_{457}$ : Reflectance at $457 \mathrm{~nm}$ measured with membranes;

${ }^{b}$ WI: whiteness index.
78.19 , and 80.02, respectively. All of these values were lower than those of the UFMs fabricated by traditional electrospinning, indicating that an obvious yellowing phenomenon occurred. The darker color of the PI-UV UFMs was attributed to charge transfer (CT) reactions caused by the irradiation of the PI fibers $[50,51]$. As the high-pressure mercury light source can emit UV irradiation at different wavelengths, in addition to photopolymerization of the polymer chains, some side reactions, such as the direct decomposition of the benzophenone units and

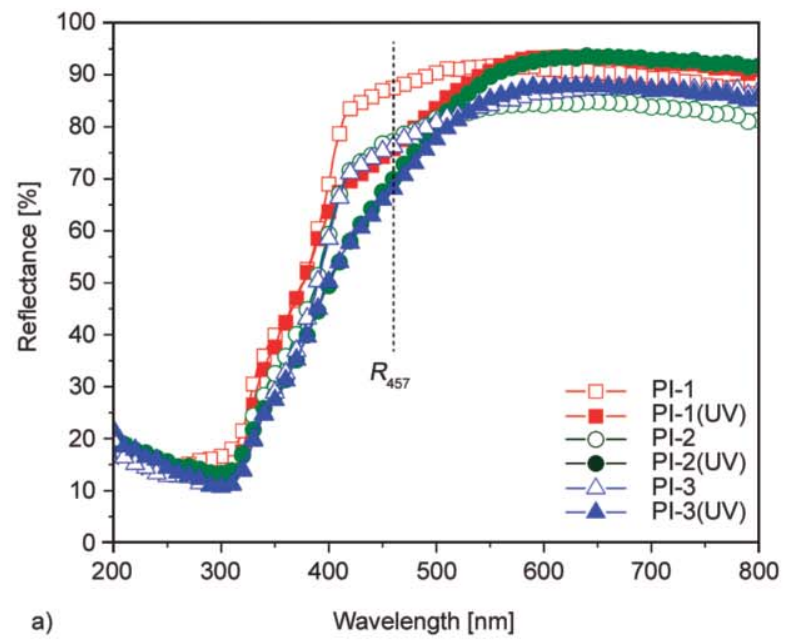

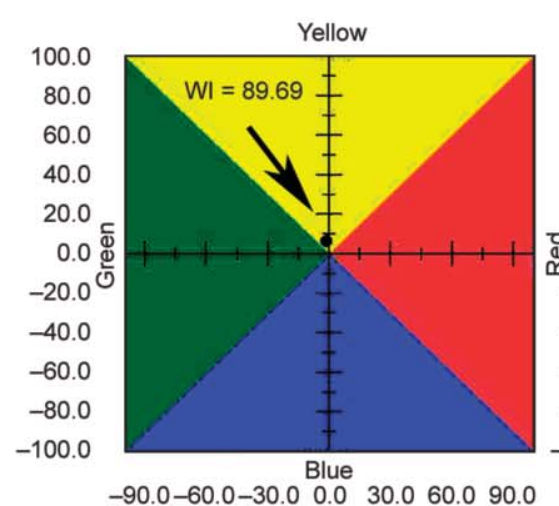

$-90.0-60.0-30.00 .030 .060 .090 .0$ PI-1

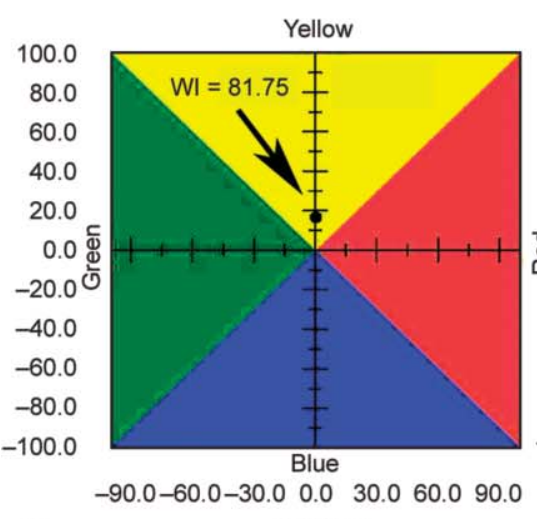

b)

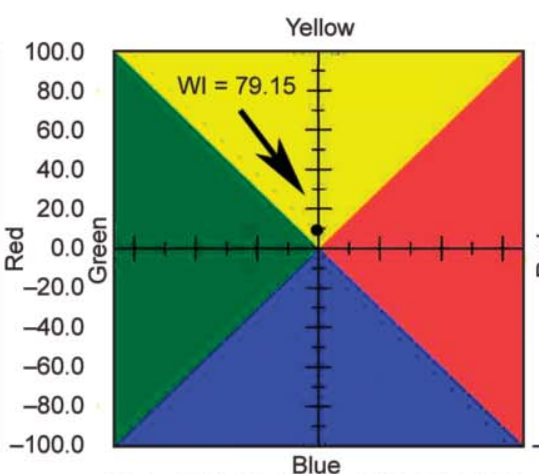

$-90.0-60.0-30.0 \quad 0.030 .060 .090 .0$

$\mathrm{PI}-2$

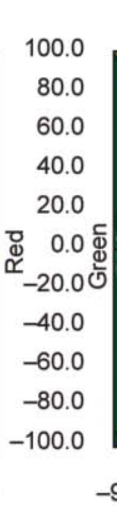

$-90.0-60.0-30.0 \quad 0.030 .060 .090 .0$

PI-2(UV)

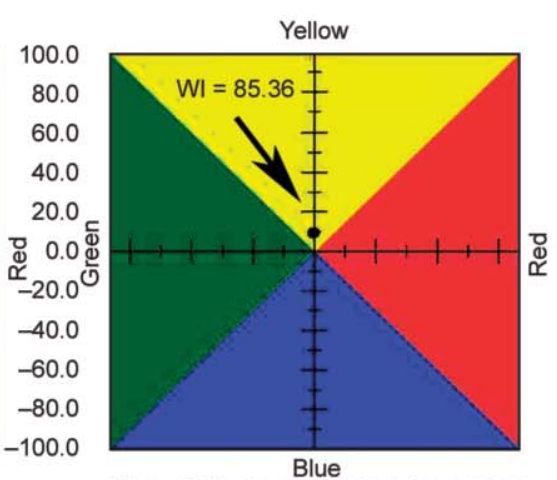

$-90.0-60.0-30.00 .030 .060 .090 .0$

$\mathrm{PI}-3$

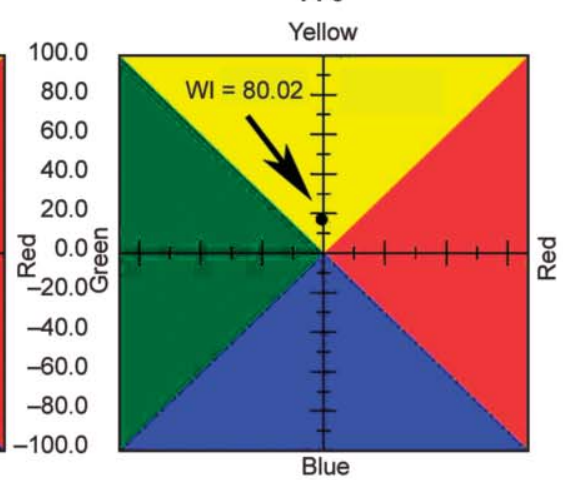

$-90.0-60.0-30.00 .030 .060 .090 .0$

$\mathrm{PI}-3$ (UV)

Figure 9. The optical properties of the PI ultrafine fibrous membranes. (a) UV-Vis spectra; (b) WI values. 
the photo-oxidation of the PIs, can also simultaneously occur, which are responsible for the deterioration of the WI values for the PI-UV UFMs.

\subsection{Wettability of the PI UFMs}

The surface energy of the fibrous membranes has been demonstrated to be negatively correlated with the contact angle of liquids, and a lower surface energy tends to impart materials with self-cleaning properties. The WCA values measured for the prepared PI and PI-UV UFMs are shown in Figure 10. The WCA values of all the UFMs were relatively high, ranging from 130.9 to $135.1^{\circ}$, indicating that these membranes are essentially hydrophobic. A possible explanation for the high WCA values is that the spun fibers with smooth surfaces and ultrathin diameters have a high surface tension, which can drive the water droplets away. Comparatively, the WCA values of the PI thin films (unfibrous membranes) were only $89.6^{\circ}$ for PI- $1,92.3^{\circ}$ for PI- 1 , and $92.1^{\circ}$ for PI-3. The WCA of the PI-3 UFM was slightly higher than those of the other two samples, indicating that microfibers with a certain diameter can form a rougher membrane surface and thus increase the contact area between the air and the droplet, resulting in a higher WCA. Conversely, fibers with excessively small diameters will form membranes with decreased roughness, thus enlarging the contact surface between the gas and liquid phases and decreasing the WCA. The WCA values of the PI-UV UFMs were slightly lower than those of the PI UFMs owing to the benzhydrol moieties generated by photoinduced crosslinking. The lone pair of oxygen in the generated hydroxyl unit can form hydrogen bonds with hydrogen from the water molecules, which decreases the hydrophobicity of the PIUV fibers. Interestingly, despite the decreased WCA values of the PI-UV samples, these membranes were still hydrophobic $\left(\mathrm{WCA}>130^{\circ}\right)$ owing to the microfibrous structure. These high WCA values indicate that the prepared PI and PI-UV UFMs are potential materials for developing self-cleaning cloth with applications in body protection and wearable devices.

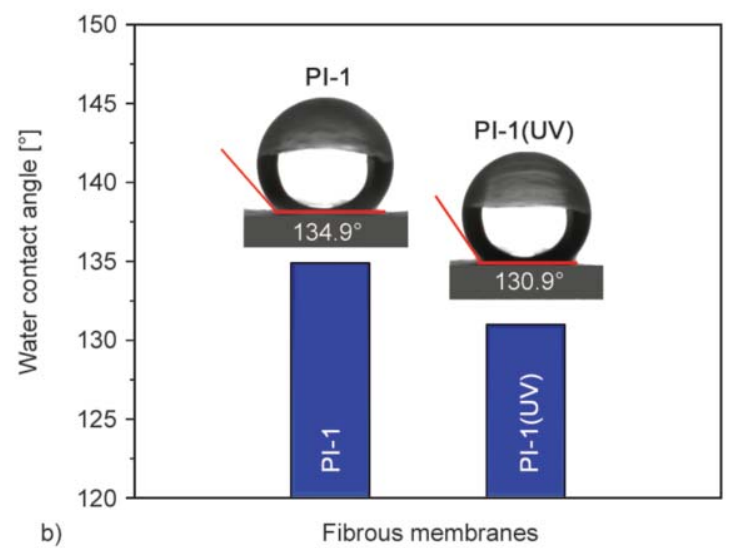

a)
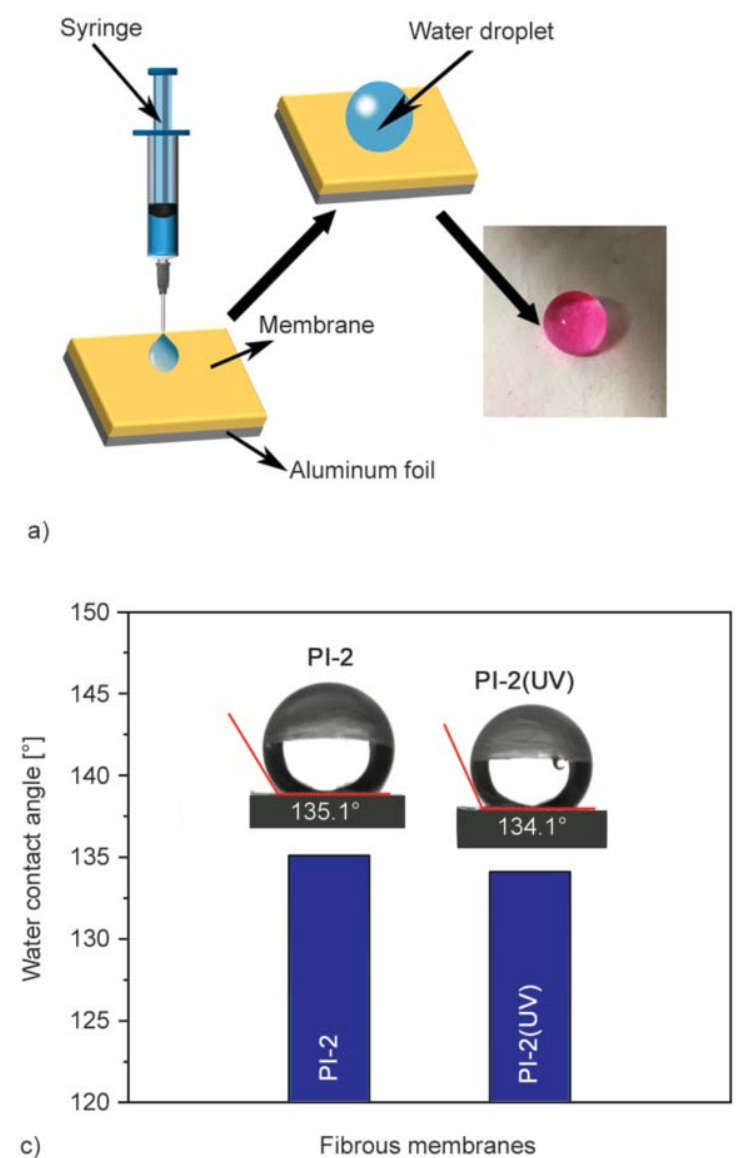

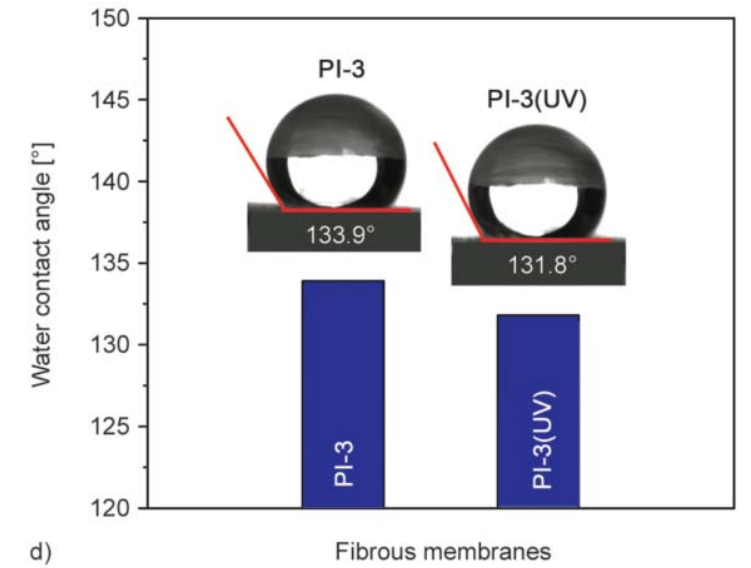

Figure 10. The water contact angle of PI ultrafine fibrous membranes. (a) Experiment schematic diagram of WCA; (b), (c), (d) WCA of UFMs conventionally and UVAES spun from PI-1 to PI-3, respectively. 


\subsection{Solvent resistance of the PI UFMs}

Finally, the solvent resistance of the fabricated UFMs was evaluated using immersion tests according to the process shown in Figure 11a with pure DMAc as the test solvent. Both of the PI and PI-UV UFMs had a fibrous appearance and adhered well to the aluminium foil substrates before immersion. During the immersion process, the PI UFMs dissolved immediately upon immersion in DMAc. In contrast, the PI-UV UFMs only swelled owing to solvent absorption but did not dissolve in the solvent, even when completely immersed. After soaking in DMAc for $30 \mathrm{~s}$, visual observations indicated that the fibrous structure of the PI UFMs disappeared completely with the aluminum foil substrate completely exposed. In contrast, the PI-UV UFMs maintained their shape with a small amount of shrinkage. The PI-UV UFMs were then dried and observed in more detail using SEM (Figure 11b). The PI-UV UFMs obtained from PI-1 and PI-3 both maintained good fibrous structures, indicating that they were completely insoluble in DMAc. In PI-UV sample obtained from PI-2, some partial bonding of the fibers was observed as well as the loss of the original structure, but dissolution was restricted to the surface of the membrane. These results demonstrate that the tremendous decrease in molecular free volume caused by successful photo-initiated crosslinking impeded the movement of the molecular chains, making the PI-UV UFMs insoluble.

\section{Conclusions}

In summary, a UVAES technology utilizing intrinsically soluble pre-imidized negative PSPIs as a fibershaping agent was successfully developed. The PSPI resins were synthesized by the one-step thermal polycondensation of the dianhydride BTDA with ortho-substituted diamines TMMDA, DMDEDA, or TEMDA, respectively. The UVAES method combined the advantages of traditional electrospinning with a photocrosslinking reaction to realizing the facile fabrication of UFMs with highly crosslinked structures. The application of UV irradiation during the electrospinning process resulted in successful in situ photocrosslinking of the PI fibers at relatively high efficiency. The average diameters of the UVAES-fabricated fibers increased slightly compared with the corresponding conventionally spun fibers. Despite the UVAES process causing a slight deterioration in the thermal decomposition temperatures, optical properties ( $R_{457}$ and $\left.\mathrm{WI}\right)$, and hydrophobic performance of the PI-UV UFMs, and the thermal dimensional stability of the fibers was improved. The PI-UV UFMs exhibited high solvent resistance against the organic solvent DMAc. The good comprehensive properties of the PI-UV UFMs indicate the potential of UVAES as a strategy for obtaining ultrafine PI fibers with high environmental stability for use in various high-tech applications.

Ultrafine fibrous membranes

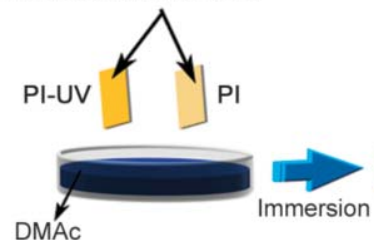

Keep for $30 \mathrm{~s}$
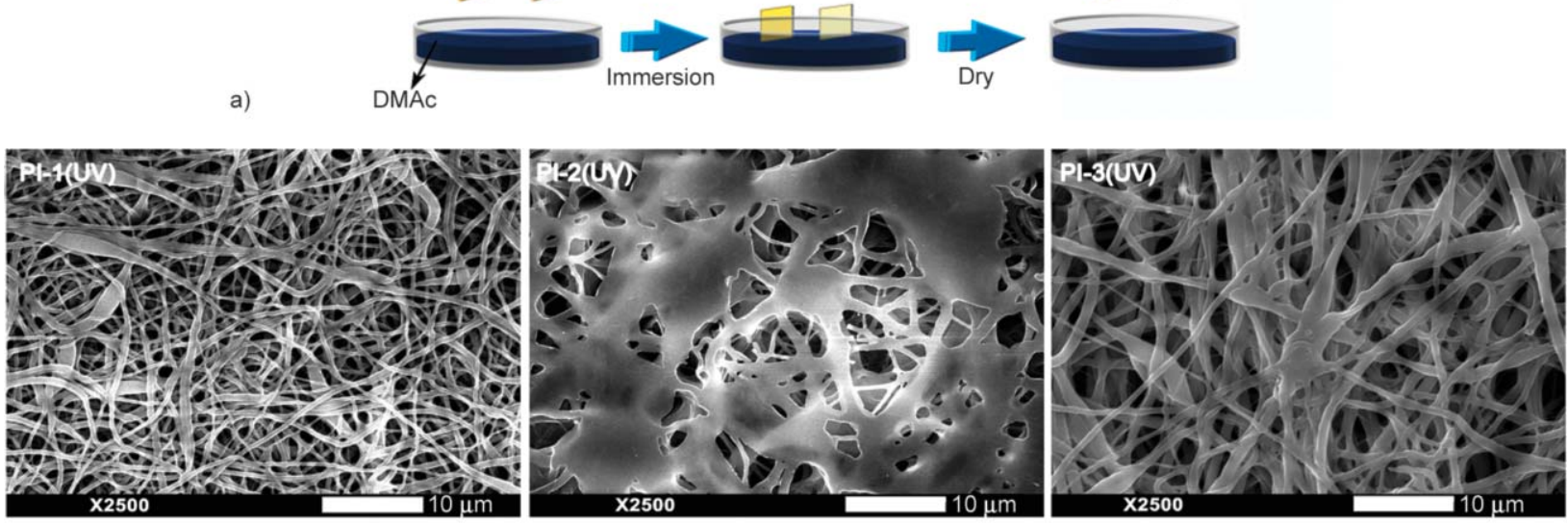

b)

Figure 11.The solvent resistance test of the PI ultrafine fibrous membranes. (a) Schematic diagram of the testing procedure; (b) SEM images of the PI UFMs after immersion in DMAc. 


\section{Acknowledgements}

This work was supported by the Shandong Key Research and Development Program (No. 2019JZZY020235) and the Fundamental Research Funds of the China University of Geosciences, Beijing (No. 2652017345).

\section{References}

[1] Jian S., Zhu J., Jiang S., Chen S., Fang H., Song Y., Duan G., Zhang Y., Hou H.: Nanofibers with diameter below one nanometer from electrospinning. RSC Advances, 8, 4794-4802 (2018). https://doi.org/10.1039/C7RA13444D

[2] Jiang S., Chen Y., Duan G., Mei C., Greiner A., Agarwal S.: Electrospun nanofiber reinforced composites: A review. Polymer Chemistry, 9, 2685-2720 (2018). https://doi.org/10.1039/C8PY00378E

[3] Huang Z-M., Zhang Y-Z., Kotaki M., Ramakrishna S.: A review on polymer nanofibers by electrospinning and their applications in nanocomposites. Composites Science and Technology, 63, 2223-2253 (2003). https://doi.org/10.1016/s0266-3538(03)00178-7

[4] Raza A., Wang J., Yang S., Si Y., Ding B.: Hierarchical porous carbon nanofibers via electrospinning. Carbon Letters, 15, 1-14 (2014).

https://doi.org/10.5714/CL.2014.15.1.001

[5] Oktay B., Kayaman-Apohan N., Erdem-Kuruca S.: Fabrication of nanofiber mats from electrospinning of functionalized polymers. IOP Conference Series: Materials Science and Engineering, 64, 012011/1-012001/5 (2014).

https://doi.org/10.1088/1757-899X/64/1/012011

[6] Gómez-Pachón E-Y., Vera-Graziano R., Campos R-M.: Structure of poly(lactic-acid) PLA nanofibers scaffolds prepared by electrospinning. IOP Conference Series: Materials Science and Engineering, 59, 012003/1012003/9 (2014).

https://doi.org/10.1088/1757-899x/59/1/012003

[7] Liao X., Dulle M., de Souza e Silva J. M., Wehrspohn R-B., Agarwal S., Förster S., Hou H., Smith P., Greiner A.: High strength in combination with high toughness in robust and sustainable polymeric materials. Science, 366, 1376-1379 (2019).

https://oi.org/10.1126/science.aay9033

[8] Duan G., Jiang S., Jérôme V., Wendorff J-H., Fathi A., Uhm J., Altstädt V., Herling M., Breu J., Freitag R., Agarwal S., Greiner A.: Ultralight, soft polymer sponges by self-assembly of short electrospun fibers in colloidal dispersions. Advanced Functional Materials, 25, 2850 2856 (2015).

https://doi.org/10.1002/adfm.201500001

[9] Gao Q., Kopera B. A. F., Zhu J., Liao X., Gao C., Retsch M., Agarwal S., Greiner A.: Breathable and flexible polymer membranes with mechanoresponsive electric resistance. Advanced Functional Materials, 30, 1907555/1-1907555/9 (2020).

https://doi.org/10.1002/adfm.201907555
[10] Xue J., Wu T., Dai Y., Xia Y.: Electrospinning and electrospun nanofibers: Methods, materials, and applications. Chemical Reviews, 119, 5298-5415 (2019).

https://doi.org/10.1021/acs.chemrev.8b00593

[11] Greiner A., Wendorff J-H.: Electrospinning: A fascinating method for the preparation of ultrathin fibers. Angewandte Chemie International Edition, 46, 5670-5703 (2007).

https://doi.org/10.1002/anie.200604646

[12] Sun B., Long Y. Z., Zhang H. D., Li M. M., Duvail J. L., Jiang X. Y., Yin H. L.: Advances in three-dimensional nanofibrous macrostructures via electrospinning. Progress in Polymer Science, 39, 862-890 (2014).

https://doi.org/10.1016/j.progpolymsci.2013.06.002

[13] Duan G., Greiner A.: Air-blowing-assisted coaxial electrospinning toward high productivity of core/sheath and hollow fibers. Macromolecular Materials and Engineering, 304, 1800669/1-1800669/5 (2019).

https://doi.org/10.1002/mame.201800669

[14] Ahmed F-E., Lalia B-S., Hashaikeh R.: A review on electrospinning for membrane fabrication: Challenges and applications. Desalination, 356, 15-30 (2015). https://doi.org/10.1016/j.desal.2014.09.033

[15] Ding Y., Hou H., Zhao Y., Zhu Z., Fong H.: Electrospun polyimide nanofibers and their applications. Progress in Polymer Science, 61, 67-103 (2016). https://doi.org/10.1016/j.progpolymsci.2016.06.006

[16] Lu F., Wang J., Chang Z., Zeng J.: Uniform deposition of Ag nanoparticles on $\mathrm{ZnO}$ nanorod arrays grown on polyimide/Ag nanofibers by electrospinning, hydrothermal, and photoreduction processes. Materials and Design, 181, 108069/1-108069/9 (2019).

https://doi.org/10.1016/j.matdes.2019.108069

[17] Guo Y., Yang X., Ruan K., Kong J., Dong M., Zhang J., Gu J., Guo Z.: Reduced graphene oxide heterostructured silver nanoparticles significantly enhanced thermal conductivities in hot-pressed electrospun polyimide nanocomposites. ACS Applied Materials and Interfaces, 11, 25465-25473 (2019). https://doi.org/10.1021/acsami.9b10161

[18] Lasprilla-Botero J., Álvarez-Láinez M., Lagaron J-M.: The influence of electrospinning parameters and solvent selection on the morphology and diameter of polyimide nanofibers. Materials Today Communications, 14, 1-9 (2018). https://doi.org/10.1016/j.mtcomm.2017.12.003

[19] Zhai T-L., Du Q., Xu S., Wang Y., Zhang C.: Electrospun nanofibrous membrane of porous fluorine-containing triptycene-based polyimides for oil/water separation. RSC Advances, 7, 22548-22552 (2017). https://doi.org/10.1039/c7ra01614j

[20] Yao J., Pantano M. F., Pugno N. M., Bastiaansen C. W. M., Peijs T.: High-performance electrospun co-polyimide nanofibers. Polymer, 76, 105-112 (2015). https://doi.org/10.1016/j.polymer.2015.08.053 
[21] Wang D., Yu J., Duan G., Liu K., Hou H.: Electrospun polyimide nonwovens with enhanced mechanical and thermal properties by addition of trace plasticizer. Journal of Material Science, 55, 5667-5679 (2020). https://doi.org/10.1007/s10853-020-04402-2

[22] Yao K., Chen J., Li P., Duan G., Hou H.: Robust strong electrospun polyimide composite nanofibers from a ternary polyamic acid blend. Composite Communications, 15, 92-95 (2019). https://doi.org/10.1016/j.coco.2019.07.001

[23] Goponenko A. V., Hou H., Dzenis Y. A.: Avoiding fusion of electrospun 3,3',4,4'-biphenyltetracarboxylic dianhydride-4,4'-oxydianiline copolymer nanofibers during conversion to polyimide. Polymer, 52, 3776-3782 (2011). https://doi.org/10.1016/j.polymer.2011.06.023

[24] Cheng C., Chen J., Chen F., Hu P., Wu X-F., Reneker D-H., Hou H.: High-strength and high-toughness polyimide nanofibers: Synthesis and characterization. Journal of Applied Polymer Science, 116, 1581-1586 (2010). https://doi.org/10.1002/app.31523

[25] Chen Y., Han D., Ouyang W., Chen S., Hou H., Zhao Y., Fong H.: Fabrication and evaluation of polyamide 6 composites with electrospun polyimide nanofibers as skeletal framework. Composites Part B: Engineering, 43, 2382-2388 (2012). https://doi.org/10.1016/j.compositesb.2011.11.071

[26] Gautam A. K., Lai C., Fong H., Menkhaus T. J.: Electrospun polyimide nanofiber membranes for high flux and low fouling microfiltration applications. Journal of Membrane Science, 466, 142-150 (2014). https://doi.org/10.1016/j.memsci.2014.04.047

[27] He Y., Han D., Chen J., Ding Y., Jiang S., Hu C., Chen S., Hou H.: Highly strong and highly tough electrospun polyimide/polyimide composite nanofibers from binary blend of polyamic acids. RSC Advances, 4, 59936 59942 (2014).

https://doi.org/10.1039/c4ra10075a

[28] Fukushima S., Karube Y., Kawakami H.: Preparation of ultrafine uniform electrospun polyimide nanofiber. Polymer Journal, 42, 514-518 (2010).

https://doi.org/10.1038/pj.2010.33

[29] Arai T., Kawakami H.: Ultrafine electrospun nanofiber created from cross-linked polyimide solution. Polymer, 53, 2217-2222 (2012). https://doi.org/10.1016/j.polymer.2012.03.059

[30] Guo C. Y., Wang Q. W., Liu J. G., Qi L., Huangfu M. G., Wu X., Zhang Y., Zhang X. M.: Electrospun polyimide ultrafine non-woven fabrics with high whiteness and good thermal stability from organo-soluble semi-alicyclic polyimides: Preparation and properties. Express Polymer Letters, 13, 724-738 (2019).

https://doi.org/10.3144/expresspolymlett.2019.61
[31] Serbezeanu D., Popa A. M., Stelzig T., Sava I., Rossi R. M., Fortunato G.: Preparation and characterization of thermally stable polyimide membranes by electrospinning for protective clothing applications. Textile Research Journal, 85, 1763-1775 (2015). https://doi.org/10.1177/0040517515576326

[32] Rau D-A., Herzberger J., Long T-E., Williams C. B.: Ultraviolet-assisted direct ink write to additively manufacture all-aromatic polyimides. ACS Applied Materials and Interfaces, 41, 34828-34833 (2018).

https://doi.org/10.1021/acsami.8b14584

[33] Miao J-T., Ge M., Peng S., Zhong J., Li Y., Weng Z., Wu L., Zheng L.: Dynamic imine bond-based shape memory polymers with permanent shape reconfigurability for 4D printing. ACS Applied Materials and Interfaces, 11, 40642-40651 (2019).

https://doi.org/10.1021/acsami.9b14145

[34] Guo Y., Ji Z., Zhang Y., Wang X., Zhou F.: Solvent-free and photocurable polyimide inks for 3D printing. Journal of Materials Chemistry A, 5, 16307-16314 (2017). https://doi.org/10.1039/C7TA01952A

[35] Zhu M., Xiong R., Huang C.: Bio-based and photocrosslinked electrospun antibacterial nanofibrous membranes for air filtration. Carbohydrate Polymers, 205, 55-62 (2019).

https://doi.org/10.1016/j.carbpol.2018.09.075

[36] Thielke M. W., Bruckner E. P., Wong D. L., Theato P.: Thiol-ene modification of electrospun polybutadiene fibers crosslinked by UV irradiation. Polymer, 55, 5596-5599 (2014).

https://doi.org/10.1016/j.polymer.2014.09.002

[37] Shanmuganathan K., Elliot S-M., Lane A-P., Ellison C-J.: Highly stretchable thermoset fibers and nonwovens using thiol-ene photopolymerization. ACS Applied Materials and Interfaces, 6, 14259-14265 (2014).

https://doi.org/10.1021/am503563q

[38] Gupta P., Trenor S-R., Long T-E., Wilkes G-L.: In situ photo-cross-linking of cinnamate functionalized poly (methyl methacrylate-co-2-hydroxyethyl acrylate) fibers during electrospinning. Macromolecules, 37, 9211-9218 (2004). https://doi.org/10.1021/ma048844g

[39] Qi L., Guo C-Y., Fu M-G. H., Zhang Y., Yin L-M., Wu L., Liu J-G, Zhang X-M.: Enhancement of solvent resistance of polyimide electrospun mat via the UV-assisted electrospinning and photosensitive varnish. Polymers, 11, 2055/1-2055/12 (2019).

https://doi.org/10.3390/polym11122055

[40] Scaiano J. C., Netto-Ferreira J. C., Becknell A. F., Small R. D.: The mechanism of photocure of inherently photosensitive polyimides containing a benzophenone group. Polymer Engineering and Science, 29, 942-944 (1989). https://doi.org/10.1002/pen.760291411

[41] Ree M., Chen K-J. R., Czornyj G.: Effects of UV exposure and thermal history on properties of a preimidized photosensitive polyimide. Polymer Engineering and Science, 32, 924-930 (1992). https://doi.org/10.1002/pen.760321403 
[42] Rohde O., Smolka P., Falcigno P. A., Pfeifer J.: Novel auto-photosensitive polyimides with tailored properties. Polymer Engineering and Science, 32, 1623-1629 (1992). https://doi.org/10.1002/pen.760322115

[43] Rich D-C., Sichel E-K., Cebe P.: Curing study of a preimidized photosensitive polyimide. Polymer Engineering and Science, 36, 2179-2187 (1996). https://doi.org/10.1002/pen.10615

[44] Lin A. A., Sastri V. R., Tesoro G., Reiser A., Eachus R.: On the crosslinking mechanism of benzophenone-containing polyimides. Macromolecules, 21, 1165-1169 (1988).

https://doi.org/10.1021/ma00182a052

[45] Hasegawa M., Horie K.: Photophysics, photochemistry, and optical properties of polyimides. Progress in Polymer Science, 26, 259-335 (2001). https://doi.org/10.1016/s0079-6700(00)00042-3

[46] Fouassier J. P., Allonas X., Burget D.: Photopolymerization reactions under visible lights: Principle, mechanisms and examples of applications. Progress in Organic Coatings, 47, 16-36 (2003).

https://doi.org/10.1016/S0300-9440(03)00011-0
[47] Fukukawa K-I., Ueda M.: Recent progress of photosensitive polyimides. Polymer Journal, 40, 281-296 (2008). https://doi.org/10.1295/polymj.PJ2007178

[48] Wang R., Jiang X., Yin J.: Autophotosensitive negative polyimide. Journal of Applied Polymer Science, 112, 3057-3062 (2009).

https://doi.org/10.1002/app.29895

[49] Deng J., Wang L., Liu L., Yang W.: Developments and new applications of UV-induced surface graft polymerizations. Progress in Polymer Science, 34, 156-193 (2009). https://doi.org/10.1016/j.progpolymsci.2008.06.002

[50] Rivaton A., Gardette J-L.: Photo-oxidation of aromatic polymers. Angewandte Makromolekulare Chemie, 262, 173-188 (1998). https://doi.org/10.1002/(SICI)1522-9505(19981201)261-262: $1<173::$ AID-APMC173>3.0.CO;2-O

[51] Hasegawa M., Sonobe Y., Shindo Y., Sugimura T., Karatsu T., Kitamura A.: Photophysical processes in aromatic polyimides. 2. Photoreduction of benzophenone-containing polyimide model compounds. Journal of Physical Chemistry, 98, 10771-10778 (1994). https://doi.org/10.1021/j100093a017 